Article

\title{
Architecture Discourses and Thermal Environment of Initial Urban Residence in Northeast China: A Case Study of the 156 Projects Residences
}

\author{
Rui Han ${ }^{1,2, *}$ and Daping Liu ${ }^{1, *}$ \\ 1 School of Architecture; Key Laboratory of Cold Region Urban and Rural Human Settlement Environment \\ Science and Technology of Ministry of Industry and Information Technology, Harbin Institute of Technology, \\ Harbin 150006, Heilongjiang, China \\ 2 College of Art and Design; Creative Center for ArtSciArch, Jilin Jianzhu University, \\ Changchun 130018, China \\ * Correspondence: archanrui@sina.com (R.H.); ldp_abc@sina.com (D.L.); Tel.: +86-18643199988 (R.H.)
}

Received: 18 December 2019; Accepted: 16 January 2020; Published: 17 January 2020

check for updates

\begin{abstract}
The objective of this study was to understand the development of Chinese contemporary architectural discourses and analyze the comfort of the 156 projects residences to help improve the sustainable planning and design of today's urban residential buildings. With a literature review, we described the formation and evolution process of the Soviet Union socialist realism architectural discourses that initially and deeply influenced urban residence in Northeast China and revealed the input channel and localization process of Chinese socialist realism in residential projects. Through field measurement and investigation into the building design and construction from four aspects-building group planning, unit schema standardization design, facade aesthetics, and structural design-we comparatively analyzed results that indicated the design and construction in that era. The thermal environment was also simulated using analytical software to comprehensively evaluate heat loss and heat accumulation in the cases. Finally, three passive design strategies were discussed to improve the sustainability of residence in Northeast China.
\end{abstract}

Keywords: urban residence; 156 projects; architectural discourses; socialist realism; thermal environment

\section{Introduction}

The First Five-Year Plan (1953-1957) was the starting point for China's transition from a poor agricultural into a modern industrial country. Basically, China learned and copied the successful experience of the Soviet Union's First Five-Year Plan (1928-1933), which advocated prioritizing the development of heavy industry, construction of modern cities, and improving the economic and cultural level of impoverished areas [1]. From 1953 to 1957, large-scale industrial construction activities became the main theme of China. Taking the 156 projects industrial plant construction project as the core, more than 900 large- and medium-sized industrial projects were established as supporting facilities. The industrial economic system and many modern industrial cities were initially established, which laid a foundation for China's industrialization [2]. During the construction of the 156 projects, the Soviet Union architectural discourses and advanced construction technology inspired China. From standardized design to structural optimization, from facade decoration to spatial scale control, the architectural discourses and design theory of the Soviet Union were widely popularized at that time [3]. The completion of the 156 projects accelerated the process of Chinese industrialization and improved the urban residential environment, bringing a socialist urban living culture context to China [4]. Despite these residences improving the urban residences Northeast China, which served the industrial plants, 
the special construction pattern and the socialist realism architectural discourses also hindered the progress of modern Chinese architecture.

Heilongjiang, Jilin, and Liaoning provinces are located in the northeastern region, which has a unique climate in China. This area is usually called Northeast China and has a temperate humid and semi-humid continental monsoon climate. The spring is short, with a hot and rainy summer, and long, cold, and snowy winter. The climate is characterized by cold and wind [5]. Almost one-third of the 156 projects were built in these three provinces. Figure 1 shows the locations of the three provinces locations and their distribution of the 156 projects.



Figure 1. The location of Heilongjiang, Jilin, Liaoning provinces and numbers of the 156 projects in each province in China.

Many of the 156 projects residences remain in these provinces, especially in their capitals: Harbin (capital of Heilongjiang), Changchun (capital of Jilin), and Shenyang (capital of Liaoning). They were the initial urban residences in Northeast China. Research on their architectural discourses and thermal environment is meaningful and significant. After deep investigation into the Harbin Dongqing Factory Residence (HDFR), Harbin Measuring and Cutting Tool Factory Residence (HMCTFR), Harbin Boiler Factory Residence (HBFR), Changchun FAW Group Residence (CFGR), and Shenyang Tiexi Workers Village (STWV), in addition to the literature review, we defined three research perspectives: the connections and differences in schema planning, facade decoration, and construction of building envelope.

Using on-site investigation, combined with advanced analysis and experimental methods, our goals were: (1) to objectively evaluate the promotion and restriction of the Soviet Union architectural discourses and architectural design theory on contemporary Chinese architectural design; (2) to reveals the Chinese architects' exploration of how to combine Chinese traditional architectural aesthetics in urban residences; and (3) to evaluates their thermal environment, which is the most important index of residential comfort in high latitude cold climate area, by simulating solar radiation, analyzing the wind environment, and monitoring of temperature at winter and summer solstices. 
Finally, we described the development of the architectural discourses of the initial urban residence in Northeast China, and summarized the advantages and disadvantages of the planning, design, and construction technologies, which may benefit the sustainable design of today 's urban residence in cold regions.

\section{Literature Review: The Development of Socialist Realism Architectural Discourses}

\subsection{Ideological Trend of Architectural Discourses in the Early Soviet Union (1920-1932)}

After the October Revolution (1917), the Soviet required a long period of recovery. The First Five-Year Plan (1928-1932) was launched in 1928. Heavy industry owned the majority of the development areas. During this period, many large heavy industrial plants were built, such as the Dnepr hydropower station and Magnitogorsk metallurgical plant. In 1929, the Soviet National Civil Architectural Design Institute was established to replace the private small studios, and mainly took charge of the civil architectural design of large- and medium-sized projects. With the rapid development of industry, many urban residences, schools, hospitals, and cultural palaces were built in cities, creating new industrial bases [6]. The implementation of a series of policies effectively promoted the balanced development of the regional economy and culture in the Soviet Union [7].

According to the different interpretations of the new society form, and under the influence of the new culture and art, various factions and ideological trends emerged in the architectural academic field of the Soviet Union in the 1920s, including classical revivalism, eclecticism, Russian classic, and even modernism and constructivism, which were fashionable in Western Europe at that time [8].

With the completion of the First Five-Year Plan, the Soviet Union national strength had greatly increased, which led to the centralization of politics, economy, science, and education. The government had to management this achievement through cultural control and further regulating social ideology. The national enthusiasm and populism were mobilized unprecedentedly. The classical architectural vision and design elements in Russian history returned to the public aesthetic again, which became the mainstream expression form of architecture at that time. The architectural discourses were embodied in the prevalence of eclecticism and the Baroque revivalism [9].

The rapid industrialization led to structural changes in the urban population. Many rural people moved to the cities and towns. Their aesthetic taste impacted art and architecture. Unfortunately, due to the rational architectural expression and concise façade, modernism and constructivism were unable to adapt to the aesthetic taste of these new urban residents, which was finally labeled as capitalist art by the government. After a period of exploration, they gradually faded out of the mainstream of architecture discourses in the Soviet Union [10].

\subsection{Emergence of Socialist Realism Architectural Discourses (1932-1935)}

Due to the success of the First Five-Year Plan, the Central Committee of Soviet Bolshevik Party published a document called "Reorganization of Literary and Art Groups" on 23 April 1932. It explicitly announced that various literary and art associations were disbanded, literary and art factions were abolished, and a unified creative association was established for the purpose of achieving "prosperity, innovation, correctness". Socialist realism was stipulated to be the most important creative method of literature, art, and architecture [11].

In July 1932, all private organizations of architects were abolished. The Soviet Architects Association was established. Then, the official Soviet Architecture Academy was established, which declared that the national architectural planning and design management was following the correct approach. The declaration was launched at the first conference of the Soviet Architects Association at the end of 1932, and gave a specific and clear definition of socialist realism in the field of architecture: "it means that architecture should respond to the requirements of technology, culture, and function in the most complete way with the authenticity of ideological power and artistic image. The combination and application should use the most economical and advanced technical method " [12]. The purpose of 
architecture was describing and praising people's lives and working, as well as educating the people to achieve the goals of communism.

The abstract concept of socialist realism was provided explain and express the more acceptable classical architecture with which people were familiar. The simplification of the eclecticism and the reinterpretation of the Baroque revivalism became its early representation.

\subsection{Architectural Discourses Maturity: National Form and Socialist Content (1935-1943)}

Experiencing a period of exploration and experimentation, "National Form and Socialist Content" gradually became the most important feature of Socialist Realism in the architectural academic field of the Soviet Union. National form mainly refers to the use of classical architectural elements, which include spatial scale, elements, decoration, etc. Socialist content refers to the full response to the reality of the Soviet revolutionary development, as well as the sincere praise and care of the proletariat and the people. This concept eventually led socialist realism architecture to not only meet the material and spatial needs of residences but also the government's ideological needs. In summary, buildings were required to have perfect function, reasonable economy, and high ideology to fully express the greatness and beauty of the socialist era [13].

\subsection{Emergence of Stalinist Architecture (1945-1953)}

After the World War II, from 1945 to 1953, personal worship of Stalin throughout the country reached peak. Many public buildings that glorified the supreme commander's consciousness appeared. Their common feature was continuously strengthening and shaping socialist architectural discourses, including the following meanings: invincible, powerful, and incomparably advanced. The representative buildings included the Seven Sisters of Moscow and the Palace of Science and Culture in Warsaw. Modernism and constructivism, which were prevailing in Western Europe at that time, had been completely eradicated in the Soviet Union. A tendency of reversing the architectural approach of the world appeared. Huge building volume, increasing building height, high-cost architectural decoration, and the combination of classical revivalism and Russian classicism became the fashion. Thus, the architectural discourses of this period were called Stalinist architecture [14].

\subsection{Architectural Discourses in the Era of Khrushchev (1953-1964)}

Stalin died on 5 March 1953. Khrushchev took over as general secretary of the Communist Party of the Soviet Union. He abolished Stalinist architecture and advocated for the control of the economy of buildings and the simplification of architectural form. Socialist realism was still the main architectural theory of the Soviet Union at that time. However, it gradually returned to rationality and served the people. In 1954, the conference of all Soviet architects produced the proposal of widely using the industrialization system of architecture to improve quality and reduce costs, and criticized the tendency of blindly imitating the classical form in architectural discourses. In 1955, the official Soviet Architecture Academy was abolished, and the era of Stalinist architecture ended [15].

Khrushchev was determined to replace these redundant decorative buildings with a more economical and efficient method. The new kind of building was basically designed and built in accordance with the standardized residential style. According to the wall thickness, the number of floors, roof style, and other basic building frames, which were proposed by Soviet engineers, the Soviet-style residences in all parts of the country looked almost identical [16]. Then, China formed its First Five-Year Plan. Many of the Soviet architects came to China with assistance teams though the 156 projects initiative. The Soviet Union architectural discourses, the construction technologies, and the ideology were brought to China. As a result, the industrial buildings and urban residences in this period had unique socialist realism characteristics. The development process of the Soviet Union architectural discourses from the 1920s to the 1950s is shown in Figure 2. 


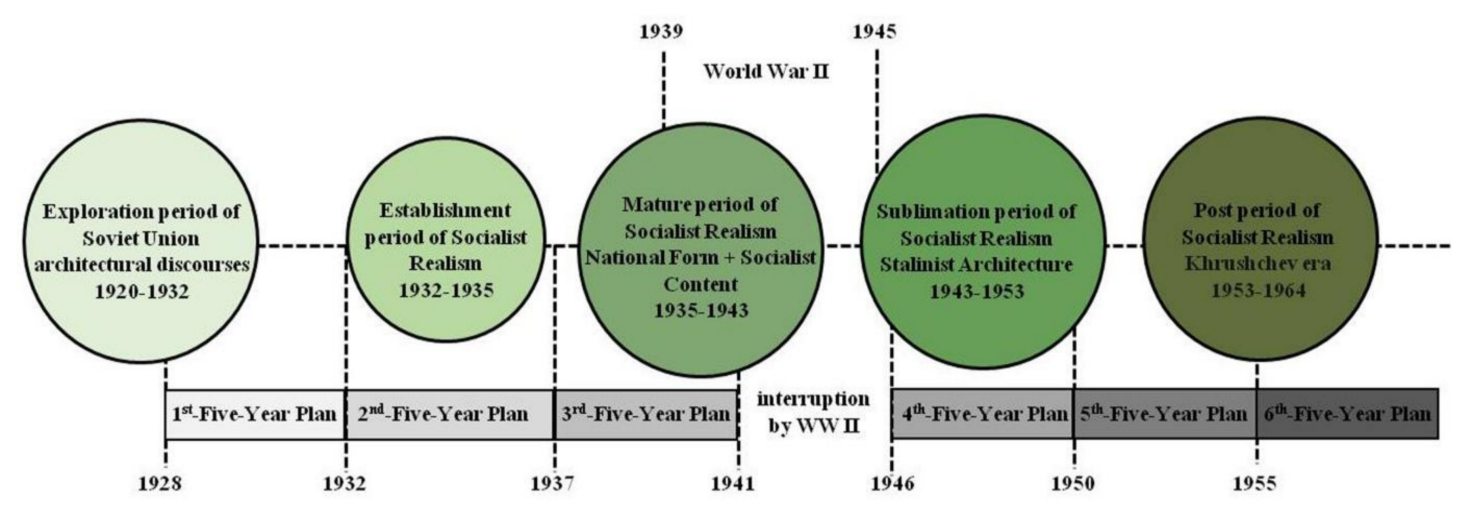

Figure 2. The development process of the Soviet Union architecture discourses(1920s-1950s).

\subsection{Input Channel of the Soviet Union Architectural Discourses}

In September 1949, K. Abramov, the Vice-Chairman of the Soviet Communist Party, led an expert group to China to assist the research into urban planning and construction in Beijing. K. Abramov stated that the new buildings in Beijing should use the national form when meeting Liang Sicheng who was in charge of the new Beijing construction. This is the first time Chinese architects came into contact with the Soviet Union architectural discourses [17]. In 1952, two Soviet experts, L. Muxin and A. Ashepkov, traveled to Beijing. The former worked in the General Construction Department of the Chinese Central Financial and Economic Committee and the latter taught architecture courses for industrial architecture and Soviet architecture history at Tsinghua University. Both of them began to systematically introduce the Soviet Union's socialist realism architectural theory to China [18].

The Soviet architectural theory was also brought back by Chinese architects who visited the Soviet Union and Eastern European countries [19]. Liang Sicheng visited the Soviet Union with the Chinese Academy of Sciences in February 1953 and met V. Moldvenov, the director of the Soviet Architecture Academy. After returning to China, Liang published an article entitled "The Soviet Union's Architectural Science Research Work" in the 11th Science Journal in 1953. He criticized the destruction of the Soviet urban architectural art, which was caused by Western constructivism, and emphasized that architecture must reflect the great eras of Lenin and Stalin, as well as serve the people. This article also commended the correct guidance of the Soviet Architecture Academy and comprehensively introduced the national form and socialist content architectural discourses [20].

\subsection{Location Process of Socialist Realism in China}

The socialist realism architectural discourses progressed from objective acceptance (1952-1953) to active integration (1953-1954) and subjective innovation (1954-1957), especially in residential construction in Northeast China. The early residential design (1952-1953) basically copied the Soviet Union socialist realism, including exquisite cornice and line foot, complicated Baroque decoration, and three sections of classicism on the facade. Figure 3 shows the three provinces' 156 projects residences in Northeast China.

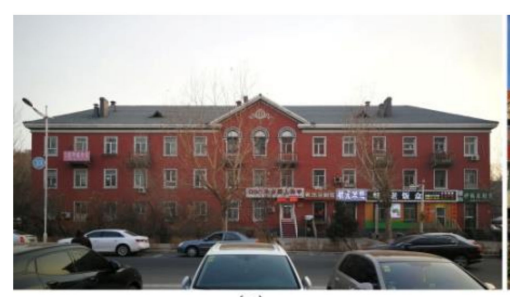

(a)

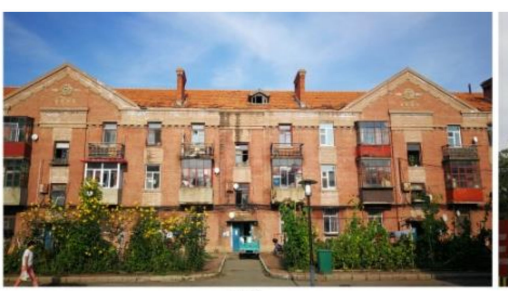

(b)

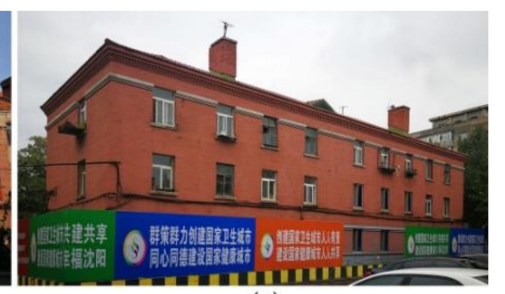

(c)

Figure 3. Residential facades: (a) CFGR block II, (b) HDFR block I, and (c) STWV. 
With the further implementation of the 156 projects (1953-1954), the construction range of the industrial plants in Northeast China continuously expanded. The Chinese architects and engineers undertook increasing numbers of design tasks in the projects. With the interpretation of national form and socialist content architectural discourses, Chinese traditional architectural elements and symbols began to appear on residential facades. The features appeared in follows aspects: the pediment with Chinese wood structure and Chinese classical decoration, the entrance, and balcony railings with Chinese traditional elements. The case residential façade is depicted in Figure 4.

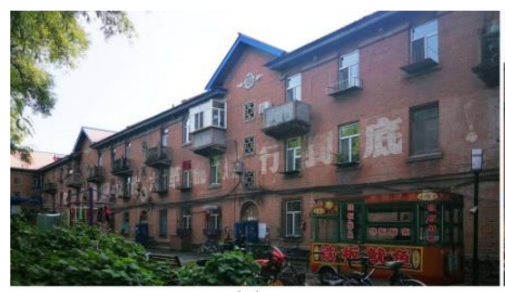

(a)

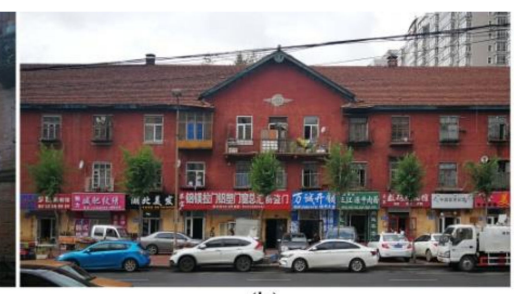

(b)

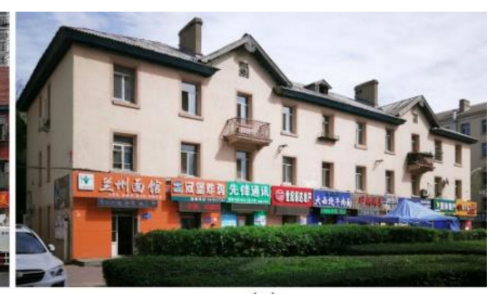

(c)

Figure 4. Residential facades: (a) HDFR block II, (b) HBFR, and (c) HMCTFR.

In the middle and later stages of the First Five-Year Plan (1954-1957), Chinese architects and engineers gradually played an increasingly important role, and even began to lead the projects. A new kind of residence with unique national form and socialist content architectural discourses and Chinese elements emerged, which were based on the Ming and Qing Dynasties, including official wooden structures. The structure system was influenced by the Soviet masonry structure [21]. The facade proportion of these residences was dignified. Chinese traditional architectural vision expresses their aesthetic taste. However, the accompanying construction costs were high. Figure 5 shows a representative case in Northeast China.

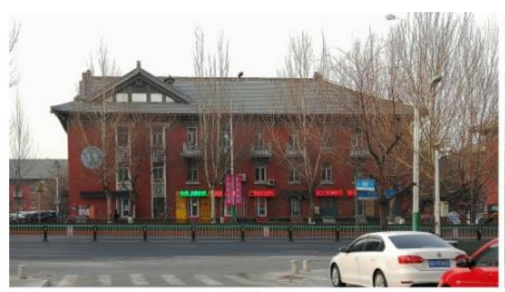

(a)

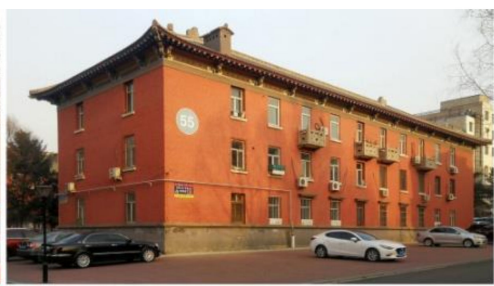

(b)

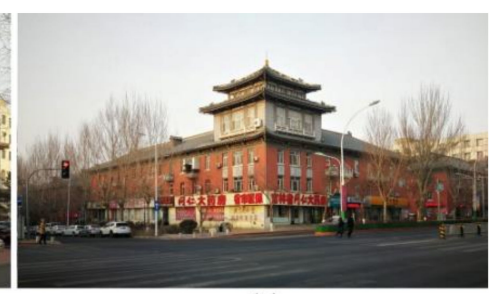

(c)

Figure 5. Residential facades:(a) CFGR block VII, (b) CFGR block VI, and (c) CFGR block VII.

According to the localization process of objective acceptance (1952-1953) to active integration (1953-1954) and subjective innovation (1954-1957), we identified the localized process of the socialist realism in residential design in Northeast China. The Chinese national form (Chinese traditional elements) gradually replaced the Soviet Union national form. From the complete copying in the early stages to the exploration in the middle stage, and then to the innovation in the later stages, this process fully embodied the development of Chinese socialist realism architectural discourses. The localization process is shown in Figure 6. 




Figure 6. The localization process of socialist realism architectural discourses in China.

\section{Methods}

\subsection{Field Measurement}

Field measurements were conducted in 2018. We investigated 75 buildings in five huge industrial residential areas in the Heilongjiang province (HDFR, HMCTFR, and HBFR), Jilin province (CFGR), and Liaoning province (STWV), which are located in Northeast China. We mainly examined building group planning, unit schema, facade design, and structure. The details and quantity of sample selection are listed in Table 1.

Table 1. The details of the 75 samples.

\begin{tabular}{cccc}
\hline Province & Case & Block Group & Quantity \\
\hline Heilongjiang & HDFR & Block I, II, III & 15 \\
& HMCTFR & Minsheng Road Block & 10 \\
& HBFR & Xusheng Street Block & 10 \\
Jilin & CFGR & Block I, II, IV, VI, VII & 32 \\
Liaoning & STWV & South No.10 Street Block & 8 \\
\hline
\end{tabular}

\subsubsection{Research on Planning}

The five cases all adopted the enclosed block group style, which is rectangular with different sizes. Inner public gardens with trees and flowers are located inside the groups. This kind of planning can create a more comfortable ecological environment and alleviate the problem of a poor sense of spatial scale caused by the large plane size of the block. The planning and spatial scale analysis of the five cases is shown in Figure 7.

We conducted the measurement with the PD-E laser rangefinder instrument (HILTI Corp. Germany), which has a measurement accuracy of $\pm 1.0 \mathrm{~mm}$ and valid range of 0.001 to $200 \mathrm{~m}$. Through actuarial measurement, we calculated the ratio between the open distance $\mathrm{D}$ and the building height $\mathrm{H}$ in all five cases as being between 1.2 and 3.0, and generally around 2.0, which creates a more comfortable external space environment. This ensures that the residents can see the entire beautiful building facade but also an adequate proportion of the sky when walking along the garden boundary and internal road. When people spend their spare time in the garden, they feel a certain sense of encirclement through the surrounding buildings. With the help of the visible proportion of the sky, citizens would not be too depressed or cramped. Therefore, through analyzing the above cases, the planning and inner garden design of the enclosed block group of the 156 projects residences in Northeast China were found to be scientific and reasonable.

\subsubsection{Research on Schema}

After measurement of 75 buildings in the five cases, we found that all the buildings mainly adopted a standardized modular design with three common building composite patterns: $\mathrm{U}, \mathrm{L}$, and 
linear. Each building had the following features: (1) composed of 4 to 7 units, (2) a standard floor area of 880 to $1550 \mathrm{~m}^{2}$, (3) average height of 12-14 m, (and 4) building shape coefficient of about 0.26-0.24. Three types of building composite patterns are shown in Figure 8.

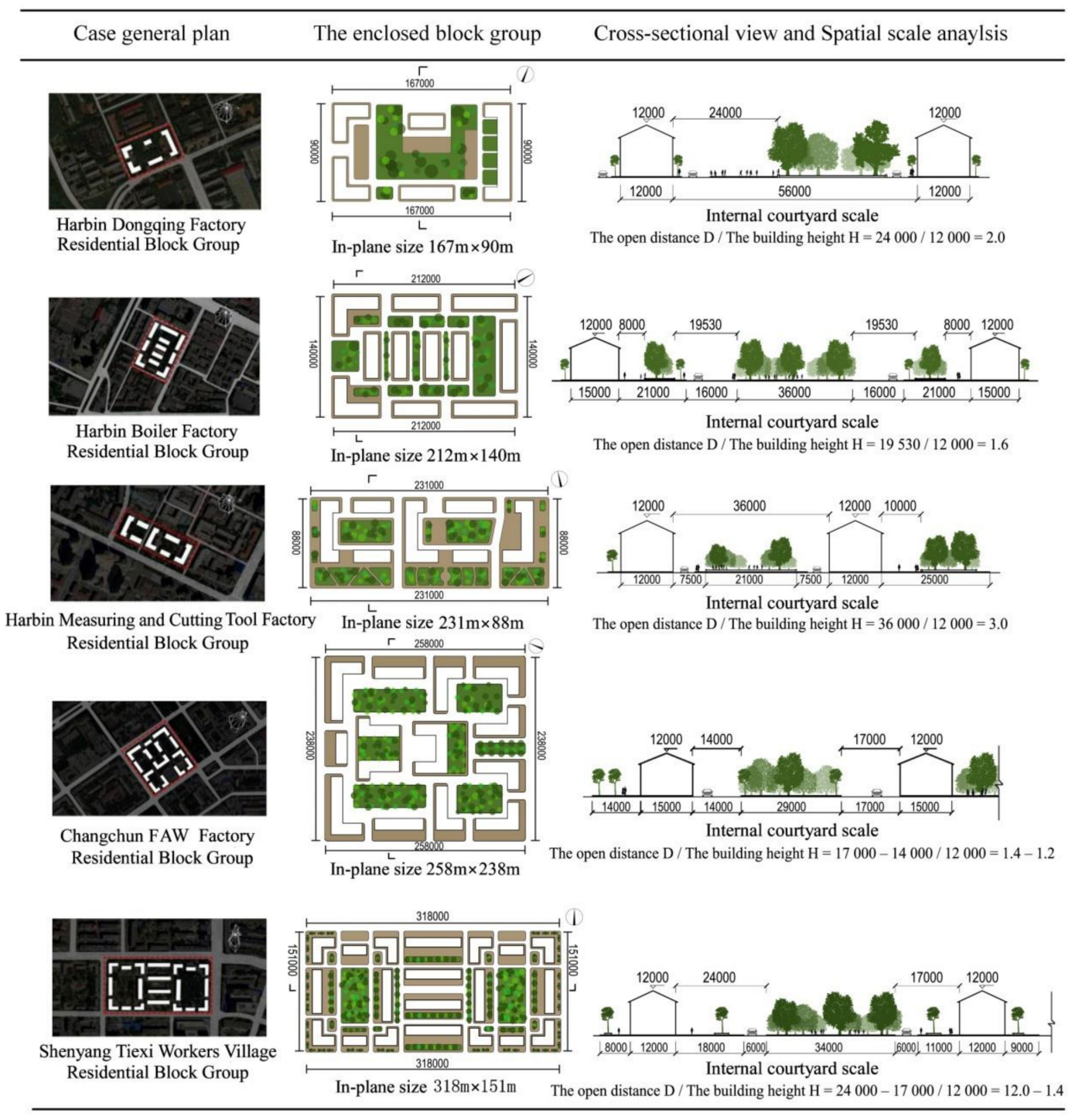

Figure 7. The planning and the spatial scale analysis of the five cases.

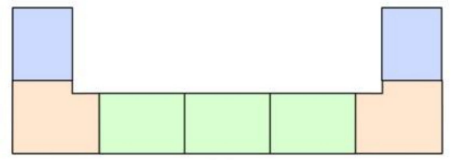

(a)

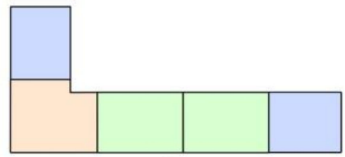

(b)

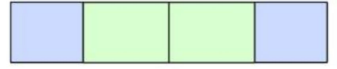

(c)

Figure 8. The building composite patterns: (a) U-shape, (b) L-shape, and (c) Linear-shape.

Due to the differences in composite pattern, three kinds of unit schemes were used: corner unit, intermediate unit, and end unit. They can be combined to create the three abovementioned building composite patterns. These three-unit schemas are shown in Figure 9. 


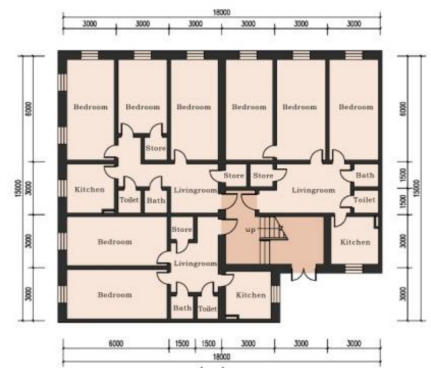

(a)

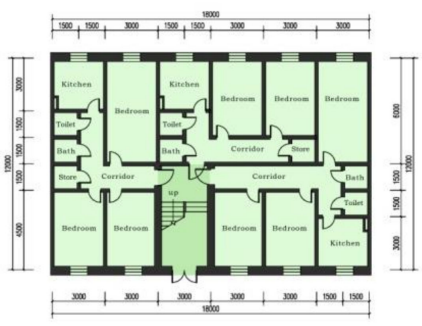

(b)

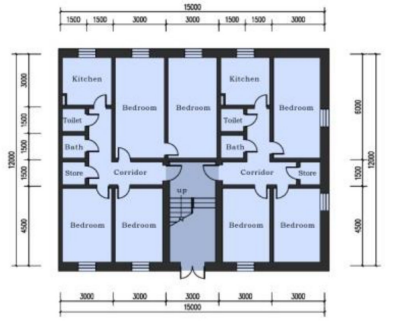

(c)

Figure 9. The unit schemes: (a) corner unit, (b) intermediate unit, and (c) end unit.

The residence design in the Soviet Union reached a high-level standardization, and the 156 projects residences in Northeast China fully copied this method. According to the functional need, every small unit apartment could be divided into large bedroom, small bedroom, kitchen, toilet, bathroom, storage room, and public space. The space forms and built-up areas are shown in Figure 10.

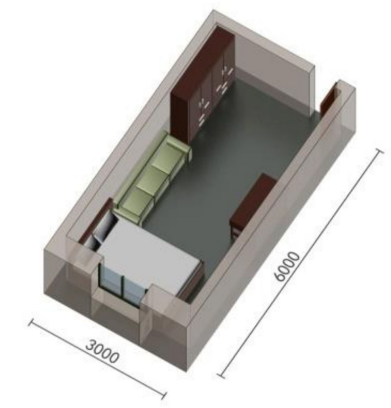

big bedroom $18 \mathrm{~m}^{2}$

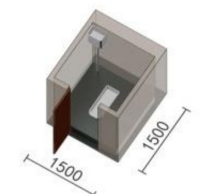

toilet $2.25 \mathrm{~m}^{2}$

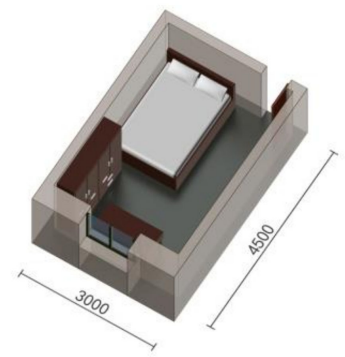

small bedroom $13.5 \mathrm{~m}^{2}$

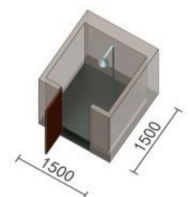

shower room $2.25 \mathrm{~m}^{2}$

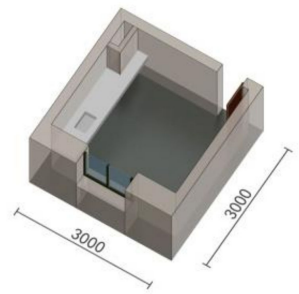

kitchen $9 \mathrm{~m}^{2}$

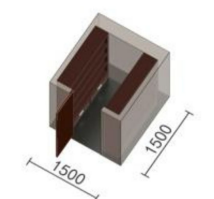

storage room $2.25 \mathrm{~m}^{2}$

Figure 10. The six basic space forms and built-up areas.

Through different combinations of the above functional spaces, the standard two- and three-bedroom apartment types were formed with a built-area of $81-54 \mathrm{~m}^{2}$. Due to location differences of the unit schemes, the internal public space was usually a long narrow corridor or a dark living room. The productions of the types were mainly sourced from the design of the living index quota of the Soviet Union socialist realism residence standard [22].

To adapt to the economic level and meet the living requirements of workers' families in Northeast China at that time, the unit apartment design of the 156 projects residences was adjusted and supplemented on the basis of the Soviet Union socialist realism residence standard, resulting in a series of new unit apartment types. By measuring 75 buildings, we identified and summarized five basic unit apartment types. After calculation, their average living index quota basically conforms to the Soviet Union's ratio of accessory area to the living area in each apartment. The five types of unit apartments are shown in Figure 11, and their living index quota calculation is listed in Table 2. 


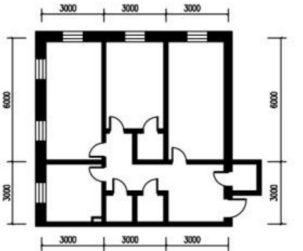

three-bedroom type A

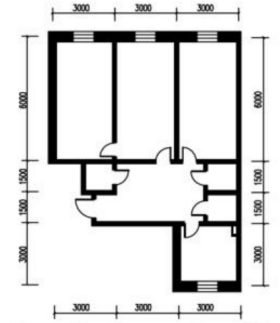

three-bedroom type B
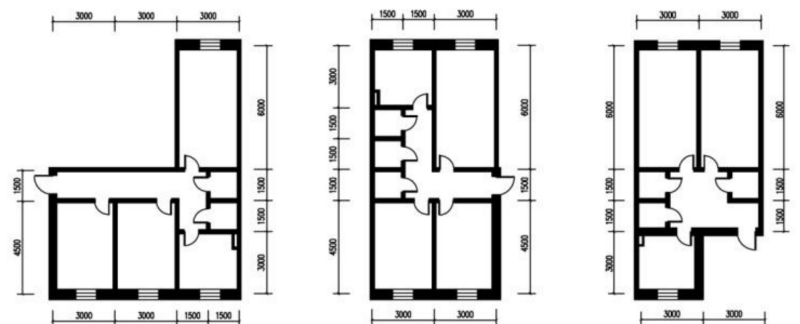

three-bedroom type C three-bedroom type $\mathrm{D}$ two-bedroom type $\mathrm{E}$

Figure 11. The five types of unit apartment.

Table 2. The living index quota calculation of the five types of unit apartment.

\begin{tabular}{cccccc}
\hline Unit Schema & $\begin{array}{c}\text { Living Area } \\
\left(\mathbf{m}^{\mathbf{2}}\right)\end{array}$ & $\begin{array}{c}\text { Kitchen Area } \\
\left(\mathbf{m}^{\mathbf{2}} \mathbf{)}\right.\end{array}$ & $\begin{array}{c}\text { Public Area } \\
\left(\mathbf{( m}^{\mathbf{2}}\right)\end{array}$ & $\begin{array}{c}\text { Accessory Area }\left(\mathbf{m}^{\mathbf{2}}\right) / \\
\text { Living Area }\left(\mathbf{m}^{\mathbf{2}}\right)\end{array}$ & $\begin{array}{c}\text { Soviet Union } \\
\text { Index Quota }\end{array}$ \\
\hline Type A & 42.6 & 7.5 & 13.3 & $25.4 / 42.6=0.59$ & $0.50-0.55$ \\
Type B & 46.2 & 7.5 & 12.7 & $24.7 / 46.2=0.53$ & $0.47-0.52$ \\
Type C & 38.9 & 7.5 & 11.3 & $22.2 / 38.9=0.57$ & $>0.55$ \\
Type D & 38.9 & 7.5 & 9.4 & $21.7 / 38.9=0.56$ & $>0.55$ \\
Type E & 30.8 & 7.5 & 9.6 & $22.1 / 30.8=0.71$ & $0.61-0.76$ \\
\hline
\end{tabular}

According to the field survey, each unit apartment is occupied by two or three families at the same time. They share one washroom, one shower room and one kitchen, which severely compromises personal privacy. The living room functions both as public activity space and traffic space. However, no sunshine enters, and the space is impractical. The living area is wasted to meet the index quota requirement. The comfort and efficiency of these unit apartments are low, which shows that the level of humanized residential design in socialist realism architectural discourses were lower, despite the form of the unit apartment being more suitable for rapid standardized construction.

\subsubsection{Facade Aesthetics}

Chinese socialist realism architectural theory exported by the Soviet Union is basically expressed into two parts: socialist content and national form. The former mainly focuses on the building block planning and unit schema in residential design. The latter mainly focuses on the residential external form, especially on the facade aesthetics and the roof typology. The facade and decoration details in different periods are shown in Figure 12.

The objective acceptance facade design (1952-1953) of the residences fully copied the Soviet Union eclecticism architectural discourses and Baroque decoration, with an elegant and complicated western aesthetic. This increased cost of construction deviated from the aesthetic taste of Chinese workers. Then, in the period of active integration (1953-1954), the design team, composed of both Soviet and Chinese architects, began to try to simplify the facade and integrate a few Chinese decorative elements, which emerged on the entrance rain cover, the balcony balustrade, and the pediment cornice. The facade aesthetic declined, resulting in an imbalance in the proportions of building components and creating an inharmonious connection between components. In the third period of subjective innovation (1954-1957), Chinese national form architectural vision had essentially been established. The official traditional wood structured building in Ming and Qing Dynasties and modern masonry buildings were combined. The façade aesthetics emphasized solemnity and majesty, as well as beauty and oriental charm. 


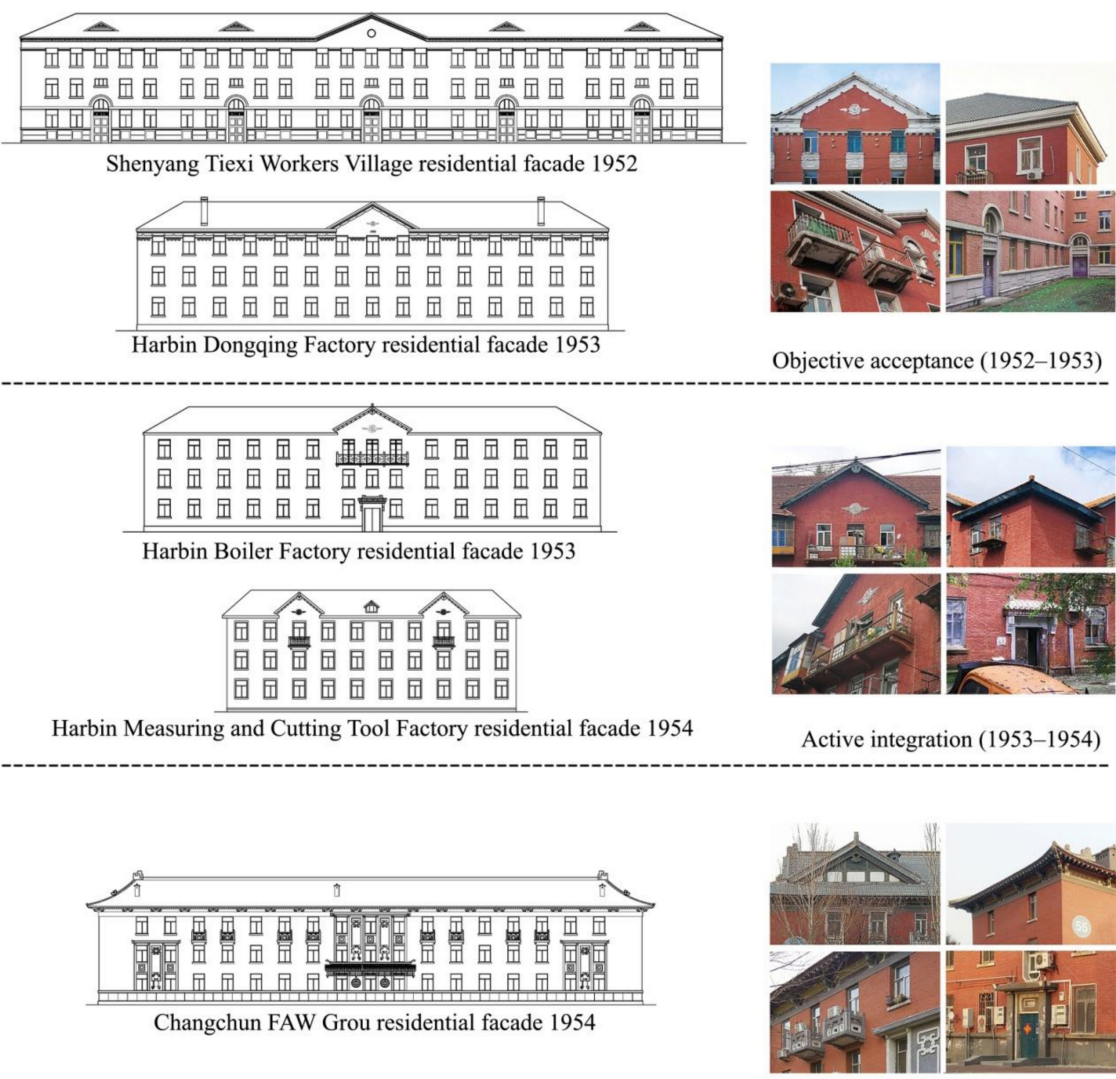

Subjective innovation (1954-1957)

Figure 12. Facade and decoration details of residences in three different periods.

The roof typology depends on the building composite pattern. There are three main typologies that all used Chinese traditional wood structure. The wooden roof truss is light and strong. According to the field survey, the top rooms are blocked from the roof truss. As a result, there exists an independent and closed space in the roof truss, which provides a good air interlayer for the top rooms to adjust the temperature in summer. The three roof typologies are shown in Figure 13.

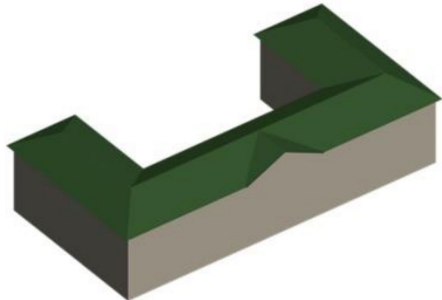

(a)

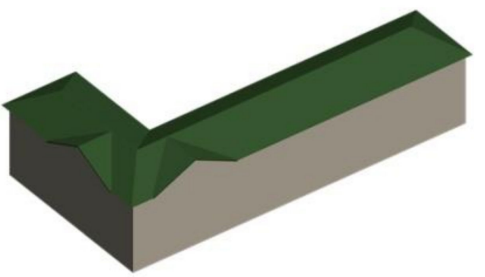

(b)

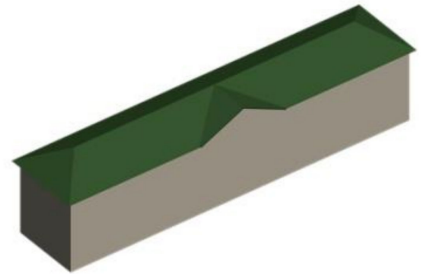

(c)

Figure 13. The three roof typologies: (a) U-shape pattern of the building, (b) L-shape pattern of the building, and (c) linear-shape pattern of the building.

\subsubsection{Structure and Envelope}

With the technical assistance from the Soviet Union, the practice of standardized residential construction was first applied in Northeast China. In September 1952, Soviet expert A. Zawaski completed a set of standard design of civil buildings, including nine kinds of residential buildings, four kinds of single dormitories, two kinds of bathrooms, and two kinds of office buildings for the Chinese 156 projects [23]. Based on this document, the designs were first applied, and construction was completed for the Shenyang Tiexi Workers Village [24]. 
The standardized design of residence depends on mature structure system research and the foundation of architectural science. To ensure reasonable and reliable structure load, we also considered the thermal performance and construction costs. After the investigation of 75 buildings in five huge industrial residential areas, we found the following regular patterns: (1) the brick masonry was widely used, (2) longitudinal walls were used as the internal structural fulcrum, (3) the prefabricated floor slab was composed of multi-rib precast slab and porous hollow precast slab, (4) and the reinforced concrete precast beam that bears all of the floor load. The prefabricated floor slab forms are shown in Figure 14.

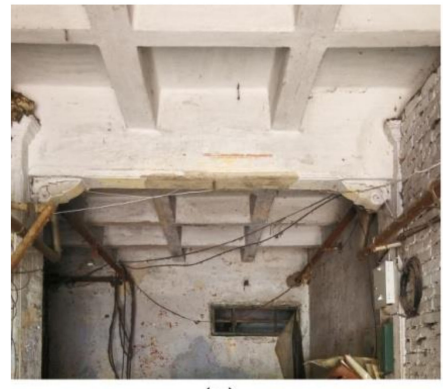

(a)

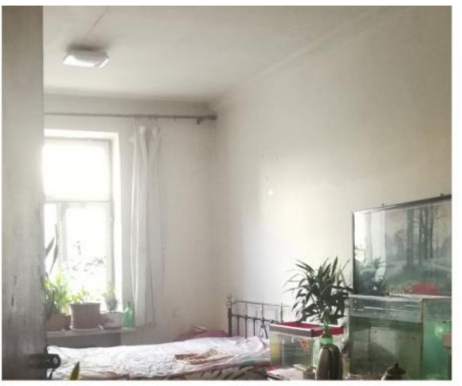

(b)

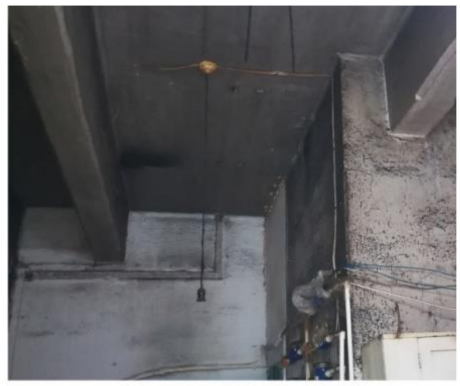

(c)

Figure 14. The prefabricated floor slab forms: (a) multi-rib precast slab in staircase, (b) porous hollow precast slab in bedroom, and (c) reinforced concrete precast beam that bears the slab in the kitchen.

To ensure the residences in the high latitude cold climate better retain heat in winter and reduce the construction cost, three different thicknesses of brick walls are widely used in the 156 projects in Northeast China: envelope, longitudinal, and non-load partition walls. Using on-site measurement, the thickness of the envelope of STWV $\left(41^{\circ} 8^{\prime} \mathrm{N}, 123^{\circ} 4^{\prime} \mathrm{E}\right)$ is $400 \mathrm{~mm}$, that of CFGR $\left(43^{\circ} 8^{\prime} \mathrm{N}, 125^{\circ} 3^{\prime} \mathrm{E}\right)$ is $500 \mathrm{~mm}$, and $700 \mathrm{~mm}$ in HDFR, HMCTFR, and HBFR $\left(44^{\circ} 4^{\prime} \mathrm{N}, 125^{\circ} 4^{\prime} \mathrm{E}\right)$. The longitudinal walls in all these cases have the same thickness of $400 \mathrm{~mm}$. The non-load partition wall is usually $150 \mathrm{~mm}$. This masonry construction method can improve the efficiency of standardized construction. Figure 15 depicts the thickness and structural form of the three kinds of walls for HBFR.

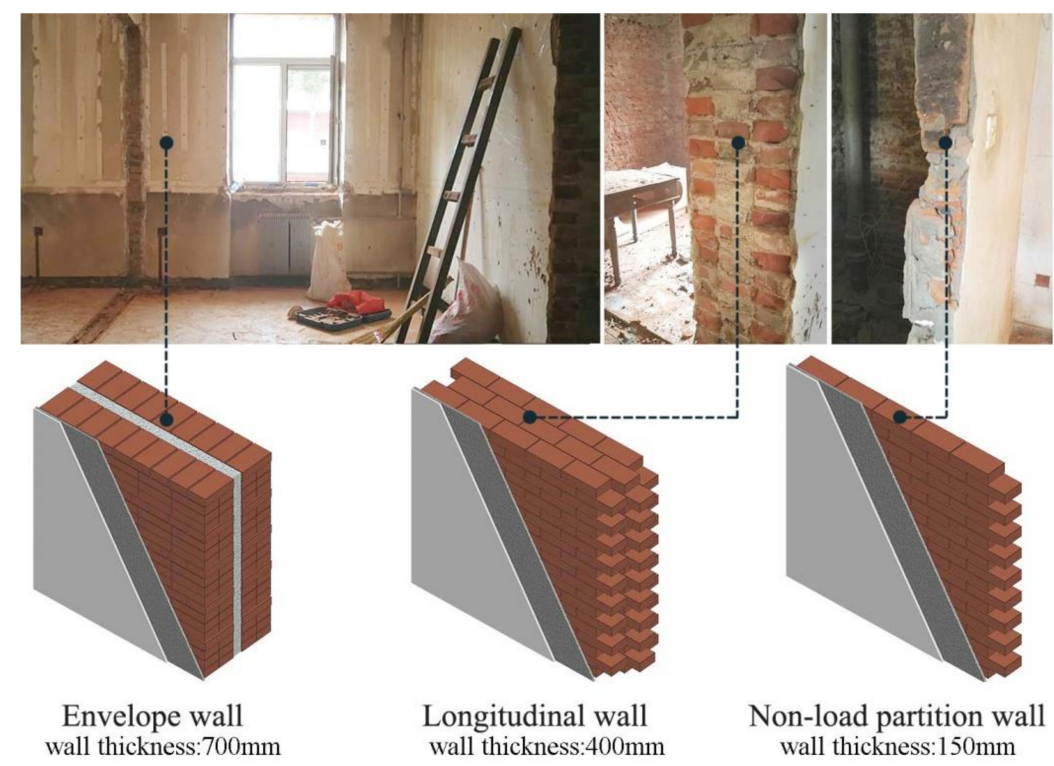

Figure 15. The masonry method of envelope wall, longitudinal wall, and non-load partition wall.

We discovered that the thickness of the envelope wall changes with increasing latitude and its position in the unit scheme. In addition to the masonry method, the thickness of the thermal insulation interlayer was also adjusted. The bricks are generally mechanical small-hole bricks with higher density. 
Unfortunately, the quality of joint filling cement is low, which allows cold air into the envelope wall and reduces the indoor temperature in winter. These residences all adopt wooden window frames and wooden entry gates, which further reduce the air-tightness of the building [25]. We then analyzed the thermal environment of these residences using simulation software.

\subsection{Simulation and Analysis}

Chinese socialist content architectural vision were built as enclosed blocks. Political ideology played a more important role than residential comfort, which reflected the new form of residential construction. However, more challenges arose, including the problem of planning orientation. To align with the direction of the public street, the plan completely ignores the direction of the sun and prevailing wind year round, which seriously affects the length of solar radiation duration per household in winter, the shadow coverage area, and the wind environment inside the block group. Through the combination of field measurement and Autodesk ${ }^{\circledR}$ Ecotect ${ }^{\circledR}$ Analysis (Autodesk ${ }^{\circledR}$, The United States) simulation, we analyzed the thermal environment of the five cases, including solar and wind environment analysis. The above indicators best reflect the residential comfort in Northeast China and provide recommendations for measures to improve residential design in this area in the future.

\subsubsection{Solar Simulation}

In this study, three three-dimensional (3D) models were built as prototypes for HBFR block I $\left(44^{\circ} 4^{\prime} \mathrm{N}, 125^{\circ} 4^{\prime} \mathrm{E}\right)$, CFGR block IV $\left(43^{\circ} 8^{\prime} \mathrm{N}, 125^{\circ} 3^{\prime} \mathrm{E}\right)$, and STWV $\left(41^{\circ} 8^{\prime} \mathrm{N}, 123^{\circ} 4^{\prime} \mathrm{E}\right)$ with the SketchUP ${ }^{\circledR}$ (Google, The United States) software. Figures 16-18 depict these models. The building shadow coverage area and solar radiation analysis were simulated using Autodesk ${ }^{\circledR}$ Ecotect ${ }^{\circledR}$ Analysis (Autodesk ${ }^{\circledR}$, The United States) software. The winter solstice algorithm was used for calculation. The specific construction of the building's envelope and roof were set according to the results of on-site inspection. The properties of each material were obtained from Autodesk ${ }^{\circledR}$ Ecotect $^{\circledR}$ Analysis (Autodesk ${ }^{\circledR}$, The United States) software.

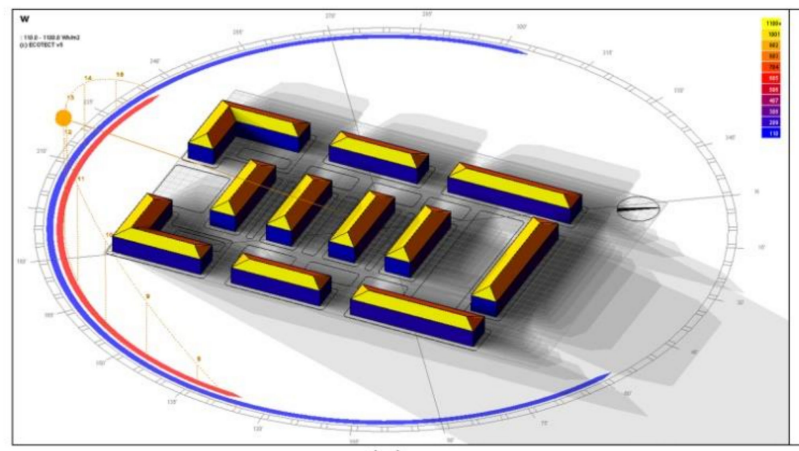

(a)

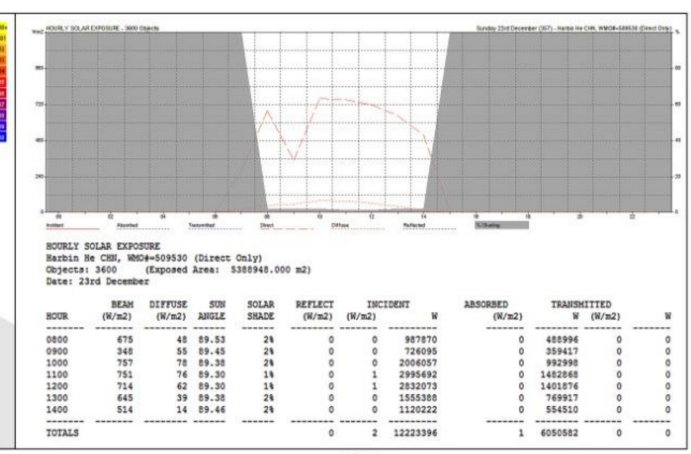

(b)

Figure 16. (a) Building shadow coverage simulation and (b) solar radiation analysis of HBFR block I.

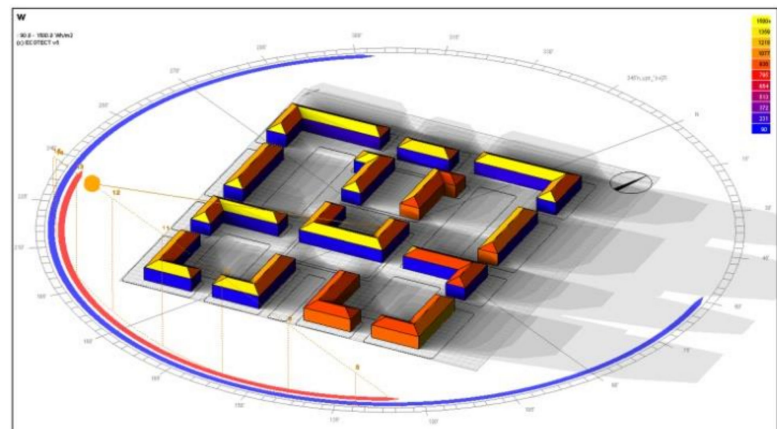

(a)

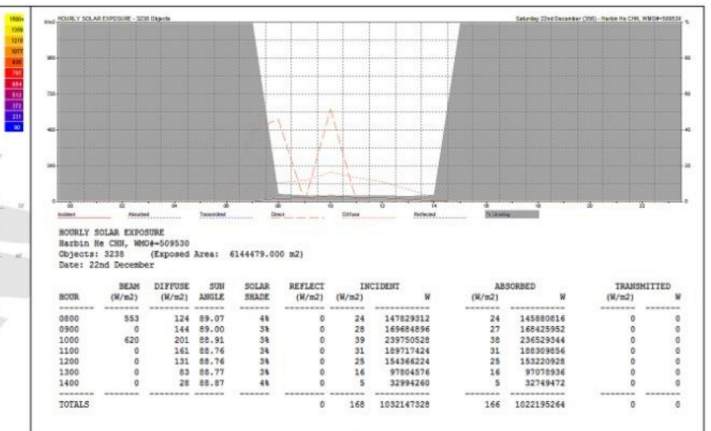

(b)

Figure 17. (a) Building shadow coverage simulation and (b) solar radiation analysis of CFGR block IV. 


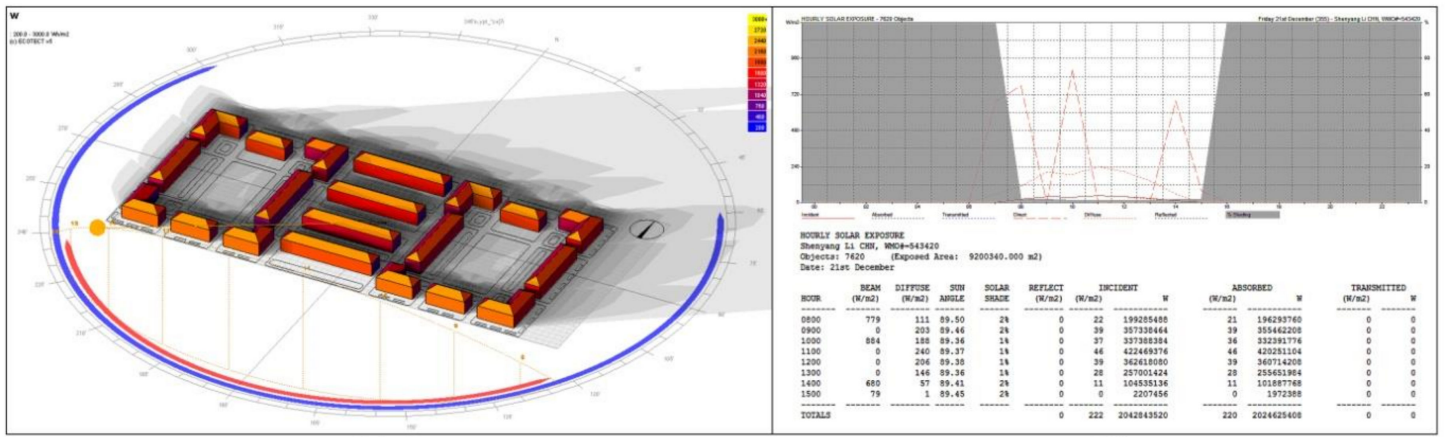

(a)

(b)

Figure 18. (a) Building shadow coverage simulation and (b) solar radiation analysis of STWV.

\subsubsection{Wind Environment Simulation and Temperature Monitoring}

Another important impact of residential comfort depends on a more comfortable wind environment through the buildings group planning and spatial scale controlling. The orientation, the shape coefficient, and the spacing between buildings will produce a different microclimate environment in the same prevailing wind area. Figures 19-21 shows the simulation of the prevailing wind frequency and average temperature distribution of HBFR block I, CFGR block IV, and STWV in winter and summer with Autodesk ${ }^{\circledR}$ Ecotect $^{\circledR}$ Analysis (Autodesk ${ }^{\circledR}$, The United States) software.

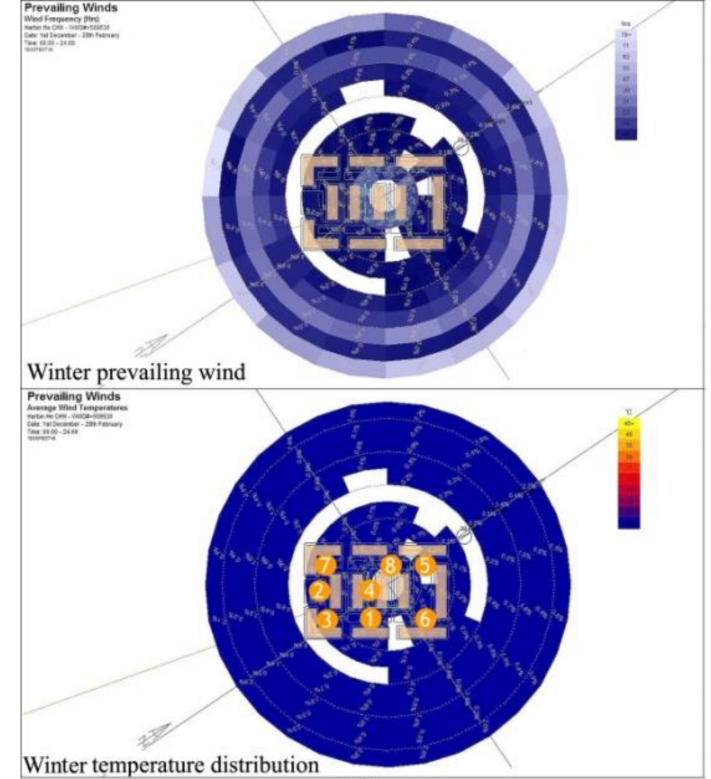

(a)

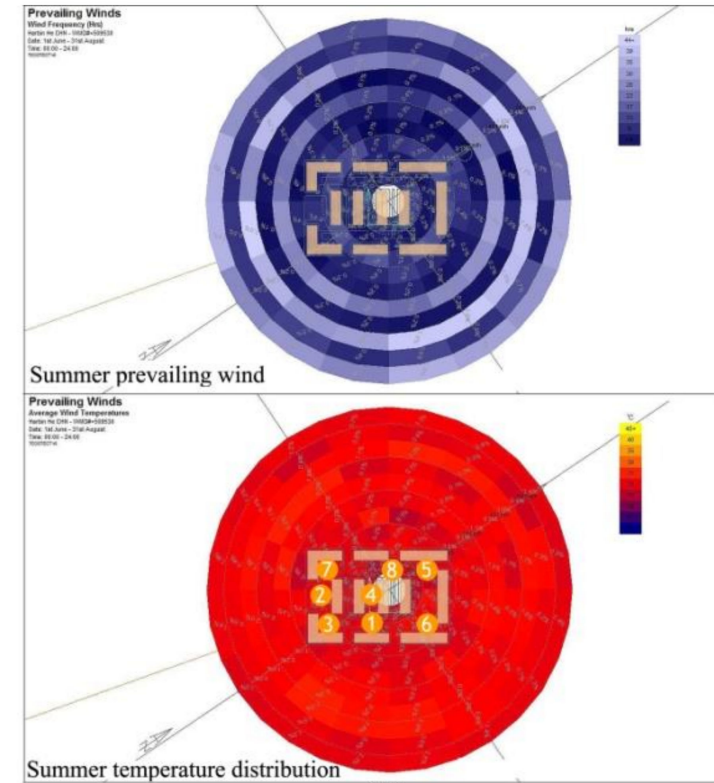

(b)

Figure 19. Prevailing wind and temperature distribution of HBFR block I: (a) winter, (b) summer.

The outdoor temperature was continuously monitored in these three cases with the TR-76Ui-H instrument (T\&D Corp. Japan), which has a measurement accuracy of $\pm 0.5^{\circ} \mathrm{C}$ and a valid range of -30 to $+80^{\circ} \mathrm{C}$. Table 3 presents the outdoor average temperature simulated and on-site monitoring results at eight key positions. The winter period was set to 00:00-24:00 (1 December 2018-28 February 2019) and the summer period was set to 00:00-24:00 (1 June 2018-31 August 2018). 


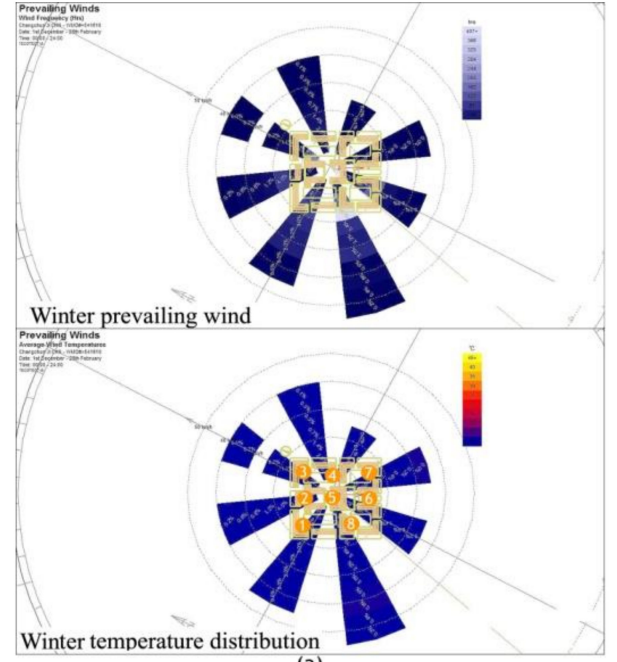

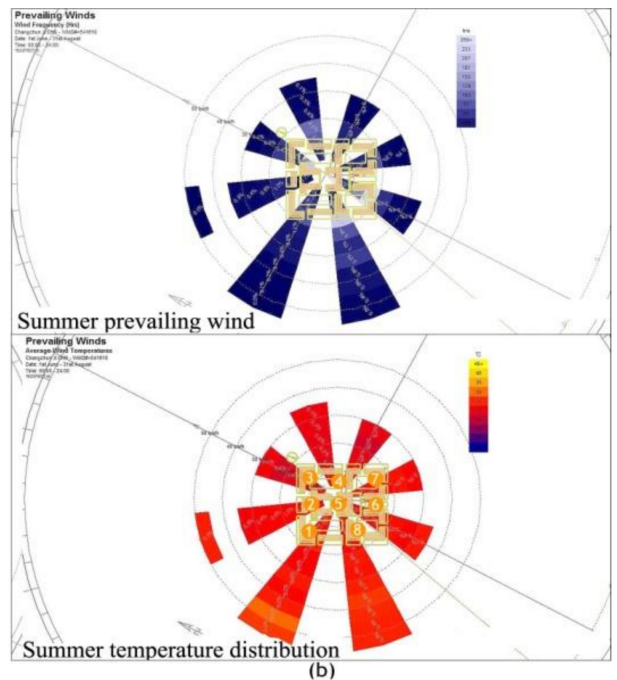

Figure 20. Prevailing wind and temperature distribution of CFGR block IV: (a) winter, (b) summer.

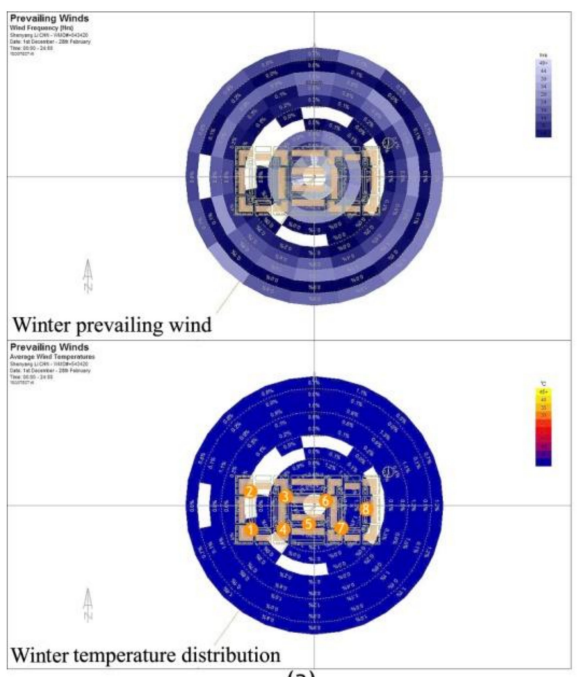

(a)



(b)

Figure 21. Prevailing wind and temperature distribution of STWV: (a) winter, (b) summer.

Table 3. The outdoor average temperature simulated and on-site monitored at key positions.

\begin{tabular}{cccc}
\hline Position & $\begin{array}{c}\text { HBFR Block I }\left({ }^{\circ} \mathbf{C}\right) \\
\text { (Simulated/On-Site Monitored) }\end{array}$ & $\begin{array}{c}\text { CFGR Block IV }\left({ }^{\circ} \mathbf{C}\right) \\
\text { (Simulated/On-Site Monitored) }\end{array}$ & $\begin{array}{c}\text { STWV }\left({ }^{\circ} \mathbf{C}\right) \\
(\text { Simulated/On-Site Monitored) }\end{array}$ \\
\hline 1-winter & $-17.5 /-18.2$ & $-13.6 /-15.1$ & $-12.1 /-12.6$ \\
2-winter & $-18.1 /-18.8$ & $-14.1 /-15.8$ & $-12.6 /-12.9$ \\
3-winter & $-17.3 /-18.3$ & $-13.7 /-15.3$ & $-12.7 /-13.3$ \\
4-winter & $-17.4 /-18.3$ & $-13.5 /-15.1$ & $-12.3 /-13.0$ \\
5-winter & $-17.9 /-18.9$ & $-13.3 /-15.0$ & $-12.3 /-12.9$ \\
6-winter & $-17.7 /-18.1$ & $-13.8 /-15.3$ & $-12.5 /-13.1$ \\
7-winter & $-17.6 /-18.2$ & $-14.0 /-15.7$ & $-12.6 /-13.3$ \\
8-winter & $-18.0 /-18.9$ & $-13.7 /-15.3$ & $-12.8 /-13.4$ \\
1-summer & $22.3 / 23.6$ & $24.2 / 24.9$ & $31.0 / 29.4$ \\
2-summer & $22.1 / 23.5$ & $24.1 / 24.7$ & $31.2 / 29.8$ \\
3-summer & $22.5 / 24.1$ & $24.2 / 24.7$ & $31.1 / 30.0$ \\
4-summer & $22.8 / 24.3$ & $24.5 / 25.4$ & $31.4 / 30.3$ \\
5-summer & $22.1 / 23.5$ & $24.8 / 25.6$ & $31.6 / 30.5$ \\
6-summer & $22.5 / 23.7$ & $23.9 / 24.5$ & $31.7 / 30.4$ \\
7-summer & $22.3 / 23.5$ & $24.2 / 24.9$ & $31.3 / 29.7$ \\
8-summer & $22.7 / 24.2$ & $23.8 / 24.5$ & $31.2 / 30.1$ \\
\hline
\end{tabular}




\section{Results and Discussion}

\subsection{Solar Simulation}

Table 4 lists the proportion of high radiation facade, medium radiation facade, low radiation facade, non-radiation facade, and all-day shadow coverage facade in the three cases. Based on the geographical and climatic characteristics of Northeast China, the simulation dates were set around the winter solstice (21-23 December 2018), analysis periods were set to 08:00-18:00.

Table 4. Statistics of solar radiation proportion of building facade in winter solstice day.

\begin{tabular}{|c|c|c|c|c|c|}
\hline Case & $\begin{array}{l}\text { High Radiation } \\
\left(700-900 \mathrm{~W} / \mathrm{m}^{2}\right)\end{array}$ & $\begin{array}{c}\text { Medium } \\
\text { Radiation } \\
\left(500-700 \mathrm{~W} / \mathrm{m}^{2}\right)\end{array}$ & $\begin{array}{l}\text { Low Radiation } \\
\left(300-500 \mathrm{~W} / \mathrm{m}^{2}\right)\end{array}$ & $\begin{array}{l}\text { Non-Radiation } \\
\left(100-300 \mathrm{~W} / \mathrm{m}^{2}\right)\end{array}$ & $\begin{array}{c}\text { All-Day Shadow } \\
\text { Coverage } \\
\left(0-100 \mathrm{~W} / \mathrm{m}^{2}\right)\end{array}$ \\
\hline HBFR block I & $5.5 \%$ & $6.5 \%$ & $15.2 \%$ & $56.4 \%$ & $22.1 \%$ \\
\hline CFGR block IV & $2.7 \%$ & $8.5 \%$ & $42.3 \%$ & $48.7 \%$ & $11.8 \%$ \\
\hline STWV & $10.1 \%$ & $23.3 \%$ & $36.4 \%$ & $31.3 \%$ & $7.7 \%$ \\
\hline
\end{tabular}

The simulation results showed that the average solar radiation received by these households is very low in winter. The unreasonable planning led to low indoor brightness and affected the indoor temperature. Taking CFGR block IV as an example, four bedrooms with different orientations were selected in the peak period of solar radiation at 10:00 during winter solstice. The indoor temperature was monitored with the TR-76Ui-H instrument (T\&D Corp. Japan), and the indoor illuminance was monitored with the TM-208 instrument (TENMARS Corp. Taiwan). Finally, the temperature and illuminance were recorded as Bedroom A: $20.5^{\circ} \mathrm{C}$ and $307 \mathrm{~lx}$, Bedroom B: $17.6^{\circ} \mathrm{C}$ and 55 lx, Bedroom C: $21.6^{\circ} \mathrm{C}$ and $382 \mathrm{~lx}$, and Bedroom D: $17.1^{\circ} \mathrm{C}$ and 35lx. Figure 22 depicts the position of the four bedrooms and the indoor temperature and illuminance monitored.
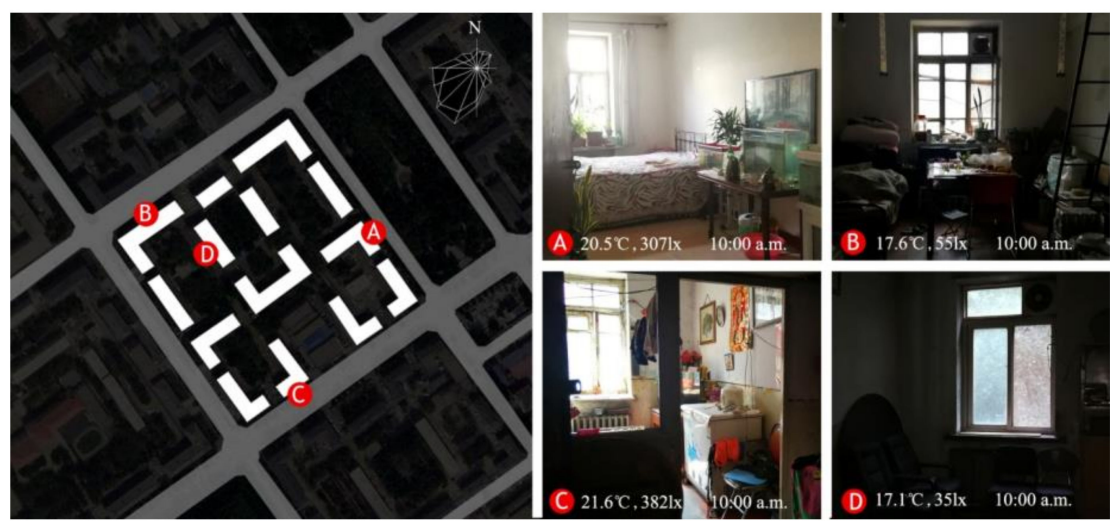

Figure 22. The temperature and illuminance monitored in four bedrooms from CFGR block IV.

The indoor temperature and illumination are far lower than the indoor comfort standard in winter, even in the bedrooms, which had the best orientation, increasing energy consumption [26-28]. The temperature depends on the indoor public heating system and the air-tightness of the windows, as well as on the low indoor solar illumination and unreasonable orientation of the building group.

\subsection{Temperature Monitoring}

The outdoor temperature monitoring was conducted at eight key positions in HBFR block, CFGR block IV and STWV, with the TR-76Ui-H instrument (T\&D Corp. Japan). The positions are shown in Figure 23. 


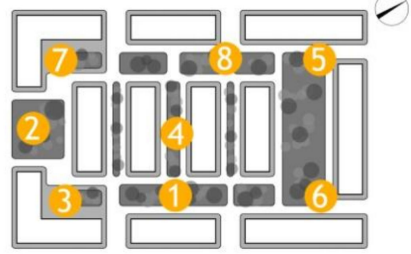

(a)

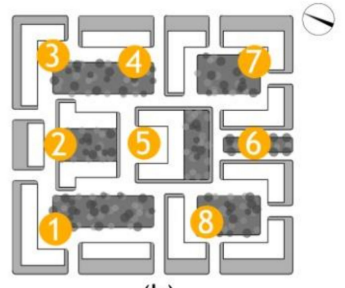

(b)

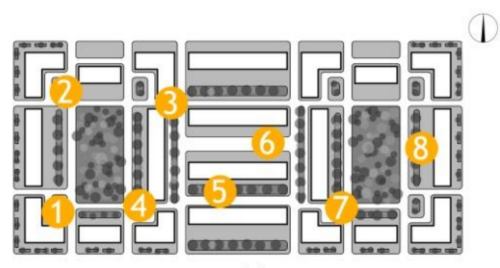

(c)

Figure 23. The 8 positions in (a) HBFR block I, (b) CFGR block IV, and (c) STWV.

The changes of temperature at key positions during the entire day (00:00-24:00) on winter and summer solstice are shown in Figures 24-26.

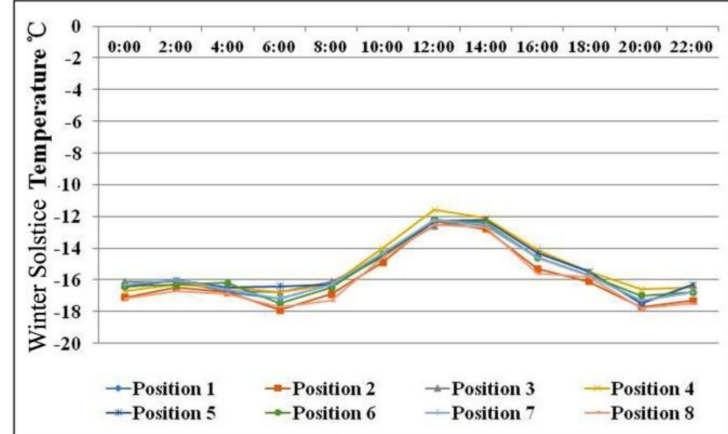

(a)

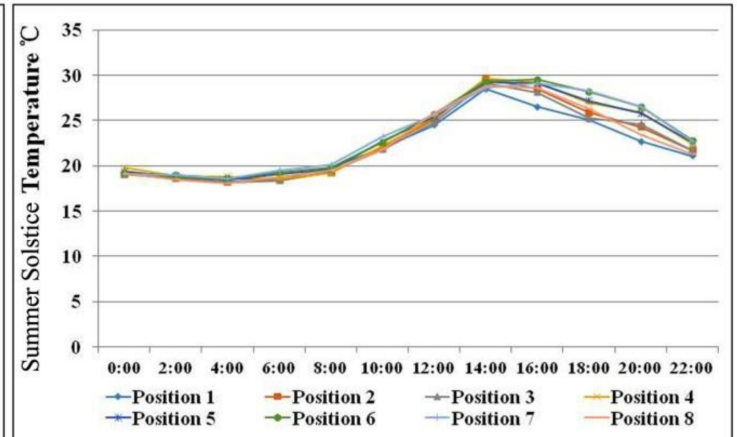

(b)

Figure 24. The changes of temperature on (a) winter solstice and (b) summer solstice of HBFR block I.

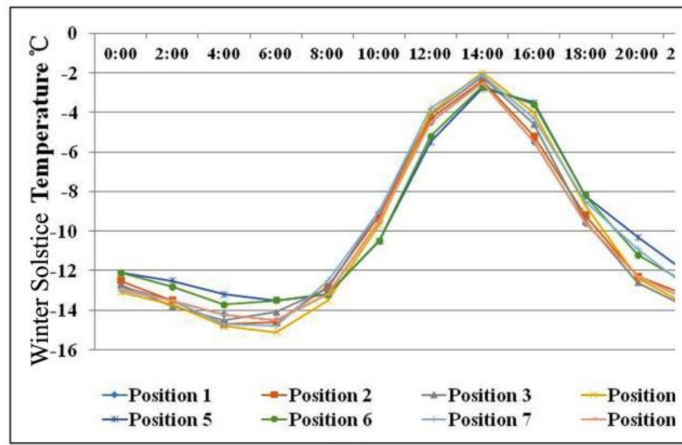

(a)

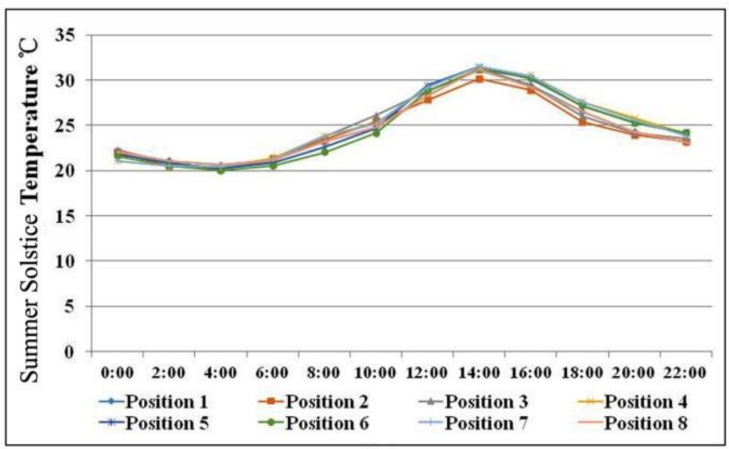

(b)

Figure 25. The changes of temperature on (a)winter solstice and (b) summer solstice of CFGR block IV.

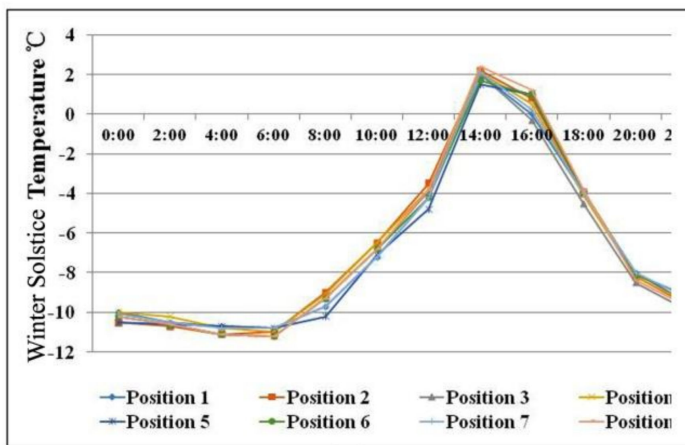

(a)

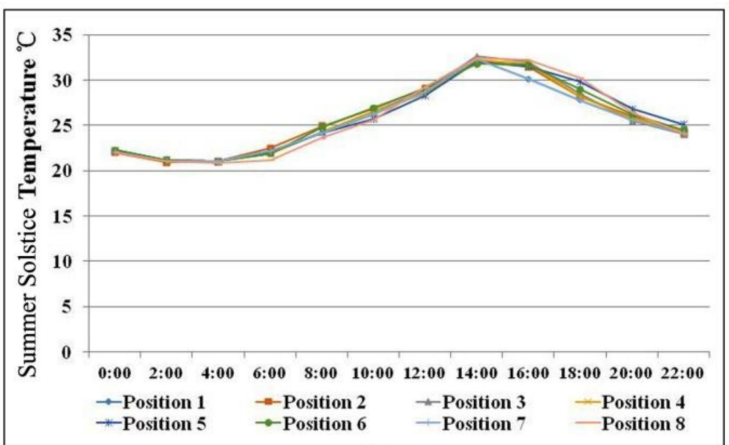

(b)

Figure 26. The changes of temperature on (a)winter solstice and (b) summer solstice of STWV. 
Northeast China is mainly affected by the cold air from Siberia in winter, resulting in a northwest prevailing wind. According to the average temperature statistics, HBFR block I and CFGR block IV have many facades directly facing the cold wind in the winter, which allows cold air to intrude into the envelopes, doors, and windows. An enclosed building plan can prevent the cold air from entering, which forms a more comfortable thermal environment in the inner garden and keeps the heat in at night. Conversely, for STWV, due to the orientation of buildings and the large spatial scale, too much cold air easily intrudes into the inner garden, which worsens the thermal environment. In summer, the southwest prevailing wind dominates in Northeast China. For HBFR block I and CFGR block IV, many facades directly face the wind, which hinders the formation of a good wind channel between buildings, resulting in the temperature rising inside the inner garden. This orientation prevents thermal heat from dissipating quickly at night. Conversely, for STWV, due to the better control of orientation and the spacing between buildings, a better wind channel can be formed, thus forming a relatively comfortable thermal environment in the inner garden.

\section{Conclusions}

Through a literature review, field measurements, simulation of the solar radiation and wind environment, and temperature monitoring of indoor and outdoor areas, we revealed the development process of socialist realism architectural discourses in initial urban residences and evaluated their residential comfort in Northeast China. Our conclusions were as follows:

Accompanying the infiltration of ideology into architectural design, the Soviet Union socialist realism architectural discourses emerged. The architectural style matured with the high concentration of the state's politics and economy, featuring eclecticism and Baroque revivalism.

The Soviet Union socialist realism architectural theory was exported into China through the 156 projects. However, over time and with localization, more traditional Chinese architectural vision and modern masonry structure were combined with the style, finally forming a uniquely Chinese socialist realism architectural vision.

The initial urban residences in Northeast China completely applied the Chinese Socialist realism architectural discourses and presented in the national form with Chinese traditional elements, despite the high construction cost. The apartment units applied high standardized modules in design, which improved construction efficiency but reduced the space use and privacy of residents to meet the requirement of index quota.

These residences presented the socialist content in the enclosed group blocks. Its spatial scale was controlled to a more suitable range $(\mathrm{D} / \mathrm{H} \approx 2.0)$, which forms a comfortable inner garden. Unfortunately, the planned orientation of the buildings was unreasonable, resulting in a lack of solar radiation $(30 \%$ of facades receiving low radiation, $43 \%$ receiving no radiation), insufficient indoor illuminance (average less than $160 \mathrm{~lx}$ ), and low indoor temperature (average less than $18^{\circ} \mathrm{C}$ ) in winter, which increases energy consumption. Due to the complexity of building planning, wind channels between the buildings do not form in summer, which prevents the heat from dissipating at night. As a result, the general thermal environment provides poor residential comfort.

Due to the unreasonable planning, these residences cannot meet the requirements for comfortable living. The unique architectural design given birth in the specific historical background has the research value for Chinese contemporary architecture. These residences are considered more suitable for conservation.

For the sustainable planning and design strategies for today's urban residence in areas with cold climates, we recommend the following:

- In Northeast China, the layout should include shorter buildings and as few convex schemas as possible to decrease the shape coefficient to less than 0.3. The design of external form can be inspired from the 156 projects residences. Because their roof typologies benefit to the insulation of the top room, and the facade aesthetics pays more attention to the decoration design than the shape design, which is more helpful for decreasing the shape coefficient. 
- The building schema should comply with the sun direction as much as possible. The distance between different residences depends on the building height and the different latitudes position. The D/H should be 1.9-2.0 in Harbin, 1.8-1.9 in Changchun, and 1.7-1.8 in Shenyang, which could improve the duration of continuous solar radiation per household during winter.

- The direction of the wind is an important consideration in the planning of the residence group. In winter, the northwest prevailing wind dominates in Northeast China. Avoiding designing rooms, windows, and doors in the northwest orientation, and increasing the thickness of the insulation layer of the envelope could prevent the cold air from intruding in winter, as well as selecting construction material with a lower heat transfer coefficient could form a more comfortable indoor thermal environment. In summer, the southwest prevailing wind dominates in Northeast China. The space between the buildings should align with the formation of the southwest prevailing wind to create wind channels and increase the ventilation of the building and allow building heat to dissipate quickly in summer.

Author Contributions: Conceptualization, R.H.; methodology: R.H. and D.L.; data analysis: D.L.; writing original draft: R.H.; review and editing: D.L. All authors have read and agreed to the published version of the manuscript.

Funding: This research was funded by the National Art Fund (2019-A-05-(373)-1080); Collaborative Education Project of Ministry of Education (201801154018); Jilin Province Social Science Fund (2018B172); Jilin Educational Science Planning Project (GH180378).

Acknowledgments: We would like to thank the anonymous reviewers for their constructive and supportive feedback.

Conflicts of Interest: The authors declare no conflict of interest.

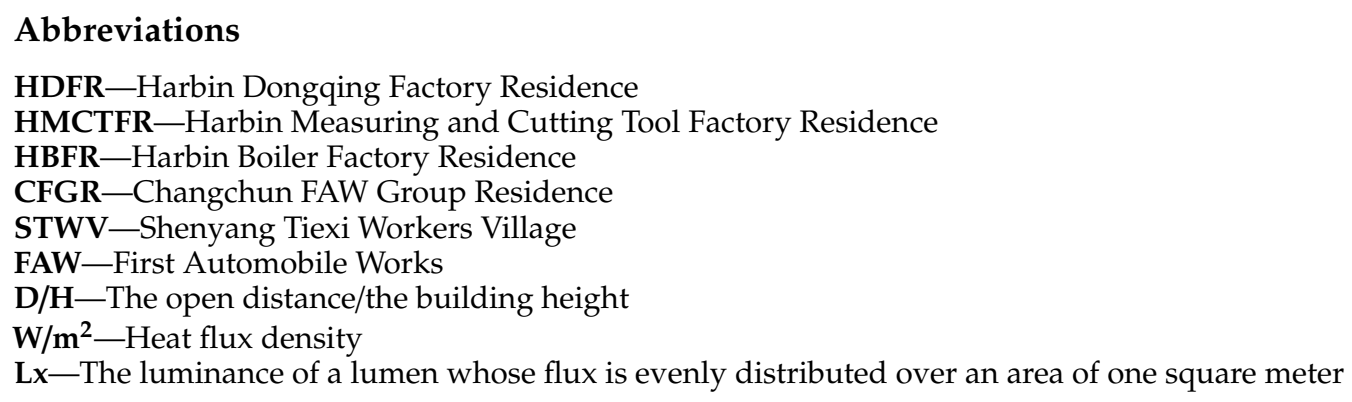

\section{References}

1. Zheng, D.; Zhang, Y. Study on the Influence of the "First-Five-Year Plan" of Soviet Union to Chinese Intellectuals in the Early 1930s. World Hist. 2009, 2, 117-128.

2. Liu, B. New Thoughts on the Scientific and Technological Value of China's Industrial Heritage. Ind. Constr. 2018, 48, 1-7.

3. Zhang, Y.; Liu, D. Research on "156 Projects" Industrial Heritage in Harbin. Res. Herit. Prot. 2018, 3, 83-89.

4. Song, K. Political Ideology and the Production of Architectural Theories in Mao's China (1949-1976). Archit. Hist. 2018, 1, 1-15. [CrossRef]

5. Tang, S. History of Urban Planning in Northeast China; Liaoning University Publishing: Liaoning, China, 1995; pp. 8-30.

6. Gu, J. Development of Urban Residential Buildings in the Soviet Union. Res. Build. Econ. 1983, 6, 46-47.

7. Tarkhanov, A.; Kavtaradze, S. Stalinist Architecture; Laurence King: London, UK, 1992.

8. Petrulis, V. Stylistic preconditions for evaluating soviet architecture. J. Archit. Urban. 2006, 30, $134-142$. [CrossRef]

9. Sadjic, D. The Edifice Complex; Chongqing Publishing: Chongqing, China, 2007; pp. 45-57.

10. Wang, Y. Soviet Architecture and Art; Heilongjiang Science and Technology Publishing: Harbin, China, 1989.

11. Ji, G. The input of Soviet Socialist Realism Architectural Theory and Its Influence on Chinese Architecture in 1950s. Era Archit. 2007, 5, 66-71. 
12. Ren, J. The History of Russian Architecture in the 20th Century: Take the Evolution of Architectural Thoughts as Clues. J. Harbin Inst. Technol. 2000, 6, 133-137.

13. Ikonnikov, A. Russian Architecture of the Soviet Period; Raduga Publishers Cop: Moscow, Russia, 1988.

14. Ashepkov, Y. Architectural history of Soviet; Architectural Engineering Publishing: Beijing, China, 1955; pp. 89-99.

15. Zubovich, K. To the New Shore: Soviet Architecture's Journey from Classicism to Standardization; UC Berkeley Previously Publishing: Berkeley, CA, USA, 2013; pp. 15-23.

16. Li, W. Architecture and Ideology: Critical Reflection on Socialist Realism Architecture. J. Huanan Univ. Technol. 2010, 12, 45-54.

17. Chen, J. "Socialist Realism" Is the Correct Method of Socialist Architectural Creation. Archit. J. 1982, 5, 43-48.

18. Yu, D. The Reconstruction of Aesthetic Taste and Literary Concept-Discussion on the Relationship between Ideology and Literature in the Early Era of China. J. Jimei Univ. 2004, 1, 95-102.

19. Zou, D. The History of Chinese Modernism Architecture; Tianjin Science and Technology Publishing: Tianjin, China, 2001.

20. Liang, S. Research on Soviet Union's Architectural Science. Sci. J. 1953, 11, 25-29.

21. Zhang, S.; Liu, D. History and information decoding of modern building bricks in Northeast China. Archit. J. 2019, 2, 112-119.

22. Kolerikov, B.; Charlesman, A.; Griberger, A. Standard Design of 2-5 Floors Residence; Architectural Engineering Publishing: Beijing, China, 1956; pp. 9-15.

23. Rubanico, B. Standard Design of Residential and Civil Buildings; Architectural Engineering Publishing: Beijing, China, 1955; pp. 19-21.

24. Wang, J. The beginning of Chinese urban unit apartment: Standard design under the influence of the Soviet Union, 1949-1957. Archit. J. 2018, 1, 97-101.

25. Rui, J.; Zhang, H.; Shi, C.; Pan, D.; Chen, Y.; Du, C. Survey on the Indoor Thermal Environment and Passive Design of Rural Residential Houses in the HSCW Zone of China. Sustainability 2019, 11, 6471. [CrossRef]

26. He, X.; Reiner, D. Electricity demand and basic needs: Empirical evidence from china's households. Energy Policy 2016, 90, 212-221. [CrossRef]

27. Ministry of Housing and Urban-Rural development of China. Design Standard for Energy Efficiency of Residential Buildings in Hot Summer and Cold Winter Zone; JGJ 134-2010; China Architecture and Building Press: Beijing, China, 2010. (In Chinese)

28. Xiong, Y.; Liu, J.; Kim, J. Understanding differences in thermal comfort between urban and rural residents in hot summer and cold winter climate. Build. Environ. 2019, 165, 106393. [CrossRef] 